\title{
Obstruktif Uyku Apne Sendromu Olan Hastalarda Ambulatuvar Kan Basıncının Önemi ve Vücut Kitle İndeksinin Nondipping Patern Üzerine Etkisi
}

\author{
The Importance of Ambulatory Blood Pressure and The Effect of Body Mass Index on \\ Nondipping Pattern in Patients with Obstructive Sleep Apnea Syndrome \\ Buket TUĞAN YILDIZ', Deniz TUNCEL BERKTAŞ ${ }^{1}$, Gülizar SÖKMEN²
}

${ }^{1}$ Kahramanmaraş Sütçü İmam Üniversitesi Tıp Fakültesi Nöroloji Anabilim Dalı, Kahramanmaraş, Türkiye
${ }^{2}$ Kahramanmaraş Sütçü İmam Üniversitesi Tıp Fakültesi Kardiyoloji Anabilim Dalı, Kahramanmaraş, Türkiye

Özet

Amaç: Obstruktif uyku apne sendromu komplikasyonu olarak görülen kardiyovasküler olaylar ve mortaliteden nondipping paternin sorumlu olduğu düşünülmektedir. Çalışmamızda vücut kitle indeksi ile nondipping patern arasındaki ilişkiyi saptamayı amaçladık.

Gereç ve Yöntemler: Hastanemiz uyku bozuklukları polikliniğinde polisomnografi ile ağır obstruktif uyku apne sendromu tanısı konulan 29 'u erkek (\%83) ve 6 'sı kadın (\%17) toplam 35 hasta çalışmaya alınmıştır. Hastaların poliklinik muayeneleri srasında kan basınçları, yaşları, cinsiyetleri, vücut kitle indeksleri kaydedilmiştir. Hastalara 24 saatlik ambulatuar tansiyon holter takılmıştır. Gece ortalama sistolik kan basıncı, gündüz ortalama sistolik kan basıncının $\% 10$ 'undan fazla düşmeyen hastalar nondipping olarak kaydedilmiştir.

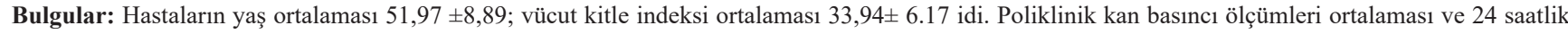
ambulatuar kan basıncı ölçümleri ortalaması Amerikan Kalp Derneği tanı kriterlerine göre hipertansiyon kriterlerini karşılamamaktaydı. Hastaların 24 (\%69)' unda nondipping paterni görülmüştür. Non dipping paterni ile vücut kitle indeksi karşılaştırıldığında aralarında anlamlı ilişki saptanmıştır (p:0,008). Hastaların vücut kitle indeksi değerleri arttıkça, sistolik kan basıncı gece değerlerinin arttığı saptanmıştır ve aralarında pozitif yönde ve anlamlı bir ilişsi vardır (r:0.389, p:0.021). Vücut kitle indeksi değerleri arttıkça, sistolik kan basıncı ortalama ve sistolik kan basıncı gündüz değerlerinin arttığı saptandı ancak aralarında anlamlı ilişki yoktu (sırasıyla p: 0,$123 ; 0.259$ ).

Sonuç: Obstruktif uyku apne sendromu hastalarının kardiyovasküler risk faktörlerinin belirlenmesinde ve takibinde poliklinik koșullarında bakılan kan basınc yeterli olmayabilir. Tanı konulan hastalardan takipleri boyunca en az bir kez 24 saatlik tansiyon holter monitorizasyonu yapılması tarafımızca önerilir. Vücut kitle indeksi nondipping patern ve morbidite üzerine direk etkilidir. Hastanın kilo vermesi non dipping patern üzerine etkili olacak, morbidite ve mortaliteyi azaltacaktır.

Anahtar kelimeler: Obstruktif uyku apne sendromu, Nondipping patern, Vücut kitle indeksi, Sempatik aktivasyon

\section{Abstract}

Objectives: It is thought that nondipping pattern is responsible for cardiovascular events and mortality in obstructive sleep apnea syndrome. In our study, we aimed to determine the relationship between body mass index and nondipping pattern.

Material and Methods: A total of 35 patients, 29 male (83\%) and 6 female (17\%) diagnosed with severe obstructive sleep apnea by polysomnography in the sleep disorders outpatient clinic of our hospital, were included in the study. Blood pressure, age, gender and body mass index of the patients were recorded during the outpatient clinic examinations. A 24-hour ambulatory blood pressure holter measurement was made. The patients whose mean systolic blood pressure at night did not decrease more than $10 \%$ of the mean systolic blood pressure during the daytime were recorded as nondipping.

Results: The mean age of the patients was $51.97 \pm 8.89$; mean body mass index was $33.94 \pm 6.17$. Mean outpatient blood pressure measurements and 24 -hour ambulatory blood pressure measurements do not meet the criteria for hypertension according to the American Heart Association diagnostic criteria. Nondipping pattern was observed in $24(69 \%)$ of the patients. When the non-dipping pattern and body mass index were compared, a significant relationship was found between them (p:0.008). As the body mass index values of the patients increased, the nighttime systolic blood pressure values increased and there was a positive and significant relationship between them (r:0.389, p:0.021). As the body mass index values increased, mean systolic blood pressure and daytime systolic blood pressure values increased, but there was no significant relationship between them (p: 0.123 ; 0.259 , respectively).

Conclusion: The blood pressure measured in outpatient clinics may not be sufficient in the determination and follow-up of cardiovascular risk factors in patients with obstructive sleep apnea syndrome. 24-hour blood pressure holter monitoring is recommended to be performed at least once during the follow-up of the diagnosed patients by us.

Body mass index has a direct effect on nondipping pattern and morbidity. Weight loss of the patient will affect the non-dipping pattern and reduce morbidity and mortality.

Keywords: Obstructive sleep apnea syndrome, nondipping, body mass index, sympathetic activation

Yazışma Adresi: Buket TUĞAN YILDIZ, Kahramanmaraş Sütçü İmam Üniversitesi Tıp Fakültesi Nöroloji Anabilim Dalı, Kahramanmaraş, Türkiye Telefon: +90 53348906 19, Mail: bukettugan@yahoo.com

ORCID No (Sirasıyla): 0000-0001-6783-2336, 0000-0003-2347-472X, 0000-0003-4440-1749

Geliş Tarihi: 13.06.2021

Kabul Tarihi: 09.08.2021

DOI: $10.17517 / \mathrm{ksutfd} .951570$ 


\section{GIRIŞ}

Obstruktif uyku apne sendromu (OUAS) prevelansı erkeklerde \%22, kadınlarda \%17 kadar yüksek bildirilmiş, sık bir hastalıktır $(1,2)$. OUAS kardiyovasküler olaylar ve mortalite ile ilişkilidir. Bu nedenle tanı ve tedavisi önemli bir hastalıktır. Sağlıklı insanlarda normalde gece sistolik kan basıncının, gündüz sistolik kan basıncının \%10 'undan daha fazla düşmesini bekleriz, buna dipping paterni denilmektedir (3). Fizyolojik olarak sempatik aktivitenin gece azalması sonu$\mathrm{cu}$, kardiyak output, periferik arter direnci ve bunlara bağlı olarak gece kan basıncı düşmektedir (4). OUAS'lı hastalarda gece sistolik kan basincında bu düşme görülmez, bu nondipping patern olarak adlandırılır. Bu hastalarda kardiyovasküler morbiditeden nondipping paternin sorumlu olduğunu kanıtlayan çalışmalar mevcuttur (5- 7).VKİ ile OUAS arasındaki ilişki eskiden beri bilinen bir durumdur. VKİ yüksekliğinin OUAS için risk faktörü olduğu çalışmalarda saptanmıştır $(8,9)$. Çalışmamızda VKİ 'nin, nondipping paterni ile ilişkisini saptamayı amaçladık.

\section{GEREÇ VE YÖNTEMLER}

Hastanemiz uyku bozuklukları polikliniğinde polisomnografi ile ağır obstruktif uyku apne sendromu (AHİ 30) tanısı konulan 29 'u erkek (\%83) ve 6 'sı kadın (\%17) toplam 35 hasta çalışmaya alınmıştır. Hastaların poliklinik muayeneleri sırasında kan basınçları, yaşları, cinsiyetleri, VKİ'leri kaydedilmiştir. Hastalara 24 saatlik ambulatuar tansiyon holter takılmıştır. Ambulatuar cihaz saat 9:00- 21:59 arasını gündüz,22:00- 8:59 arasını gece olarak otomatik hesaplamıştır. Gündüz saatlerinde 15 dakikada 1 , gece saatlerinde 30 dakikada 1 kan basıncı ölçülmüştür. Biz de, gece ortalama sistolik kan basıncı, gündüz ortalama sistolik kan basıncının \%10 'undan fazla düşmeyen hastaları nondipping olarak kaydettik.

Hafif ve orta OUAS olan, çalışmaya katılmayı kabul etmeyen, hipertansiyon ve bilinen kardiyak hastalık öyküsü olan, antihipertansif kullanan hastalar çalışmaya dahil edilmedi.

Kahramanmaraş Sütçü İmam Üniversitesi Tip Fakültesi etik komitesinden onay alınmıştır(2021/24-08). Bu çalışma Helsinki deklerasyonu prensiplerine uygun olarak yapılmıştir.

\section{İstatistiksel Analiz}

Araştırmada elde edilen veriler SPSS (Statistical Package for Social Sciences) for Windows programı kullanılarak analiz edilmiştir. Verileri değerlendirilirken tanımlayıcı istatistiksel metodlar (sayı, yüzde, ortalama, standart sapma, min, max, medyan) kullanılmıştır. İki bağımsız grup arasındaki fark için normal dağılıma sahip verilerde bağımsız t testi, veri setinin normal dağılıma sahip olmadığı durumda ise Mann Whitney U testi uygulanmıştır. Numerik değişkenler arasındaki ilişkiyi test etmek için ise Pearson korelasyon veya Spearman korelasyon uygulanmıştır.

\section{SONUÇLAR}

Hastaların yaş ortalaması 51,97 $\pm 8,89$; vücut kitle indek-

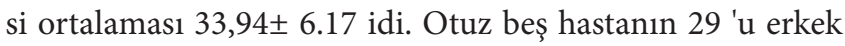
(\%83) ve 6 'sı kadın (\%17) idi. Poliklinik muayenesi sırasında ölçülen kan basınçları ortalaması 124,15 \pm 8,65 mm Hg idi ve hastaların sadece \% 13' ünün kan basıncı 140/90 mm Hg ve üzerinde ölçülmüş, hipertansiyon kriterlerini karşılamıştır. Ambulatuar kan basıncı ölçümlerinde de ortalama sistolik kan basıncı ortalaması 122,59 $\pm 8,54 \mathrm{~mm} \mathrm{Hg}$ idi. Hastaların poliklinik kan basıncı ölçümleri ortalaması ve 24 saat ambulatuar kan basıncı ölçümleri ortalamaları Amerikan Kalp Derneği (AHA)' ne göre hipertansiyon kriterlerini karşılamamaktaydı.

Poliklinik muayenesi sırasında ölçülen tek kan basıncı değeri ve ambulatuar cihaz ile ölçülen 24 saatlik kan basıncı değerleri Tablo 1'de verilmektedir.

\begin{tabular}{|c|c|}
\hline & ortalama \pm SD \\
\hline Poliklinik sistolik kan basıncı ort & $124,15 \pm 8,65$ \\
\hline Holter sistolik kan basıncı ort & $122,59 \pm 8,54$ \\
\hline Holter gündüz sistolik kan basıncı ort & $124,57 \pm 8,52$ \\
\hline Holter gece sistolik kan basıncı ort & $117,80 \pm 10,61$ \\
\hline
\end{tabular}

Hastaların 24 ( \%69)' ünde nondipping patern görülmüştür. Nondipping patern görülen hastaların VKİ ortalamaları $35.34 \pm 5.76 \mathrm{~kg} / \mathrm{m}^{2}$ hesaplanmıştır. Nondipping patern ile VKİ karşılaştırıldığında aralarında istatistiksel olarak anlamlı ilişki saptanmıştır(p:0,008)(Tablo 2). Hastaların VKİ değerleri arttıkça, sistolik kan basıncı (SKB) gece değerlerinin arttığı saptanmıştır ve aralarında pozitif yönde ve anlamlı bir ilişki vardır (r:0.389, p:0.021). VKİ değerleri arttıkça, SKB ortalama ve SKB gündüz değerlerinin arttığı saptandı ancak aralarında anlamlı ilişki yoktu (sırasıyla p: 0,123; 0.259).

\section{TARTIŞMA}

Obstruktif uyku apne sendromu üst hava yollarının geçici kollapsıyla giden, hipertansiyon, aritmi, iskemik kalp hastalığı, stroke gibi durumlara neden olan kronik bir hastalıktır (7). Morbidite ve mortalitesi yüksek olduğundan hastaların takibi iyi yapılmalı, risk faktörleri dikkatlice gözden geçirilmelidir.

Nondipping paternin kardiyovasküler morbiditenin en önemli belirleyicilerinden biri olduğunu gösteren çalışmalar vardır. Sasaki ve arkadaşları 251 OUAS'lı hastayı ortalama 43 ay boyunca izlemişler ve nondipping grupta strok, kalp yetmezliği, iskemik kalp hastalığı gibi kardiyovasküler olayların daha sık saptandığını belirtmişlerdir. Bizim çalışmamızda da hastaların poliklinikte ölçülen tek kan basıncı ortalama değerleri AHA 2020 klavuzuna göre hipertansiyon kriterlerine uymamaktayd 1 (10). Ancak hastaların 24 saatlik ambulatuvar kan basıncı değerleri analiz edildiğinde hastaların \%69' unda 
nondipping paterni görülmüştür. Bu da bize gösteriyor ki, OUAS hastalarının kardiyovasküler risk faktörlerinin belirlenmesinde ve takibinde poliklinik koşullarında bakılan kan basincı yeterli olmayabilir. OUAS tanısı konan hastalardan takipleri boyunca en az bir kez 24 saatlik tansiyon holter monitorizasyon yapılması tarafımızca önerilmektedir.

OUAS ve VKİ arasındaki ilişki uzun süredir bilinmektedir $(9,11,12)$. Özdilekcan ve ark çalışmasında VKİ arttıkça, OUAS şiddetinin arttı̆̆ VKİ arttıkça apne-hipopne indeksinin arttığı saptanmıștır(9, 13). Ancak bildiğimiz kadarıyla OUAS' 11 hastalarda VKİ' nin nondipping patern ile ilişkisini araştıran bir çalışma bulunmamaktatır. Çalıșmamızda nondipping paternin, VKİ ile istatistiksel olarak ilişkili olduğunu $\operatorname{saptad} \mathrm{k}(\mathrm{p}=0,008)$. Ayrıca bulgularımız VKİ' leri arttıkça gece sistolik kan basıncı ortalamasının arttığını gösterdi, halbuki gündüz sistolik kan basıncı ortalaması ile 24 saatlik sistolik kan basıncı ortalaması arasında böyle bir ilişki saptanmadı. Gece olan sistolik kan basıncı düşmelerinden sempatik aktivitenin gece azalmasının sorumlu olduğu düşünülmektedir(4). Kilo ile sempatik sinir sistemi aktivasyonu arasında ilişki olduğunu gösteren yayınlar mevcuttur(14, 15,16). Obez kişilerde artmış plazma ve üriner norepinefrin düzeyleri saptanmıştır(17, 18). Lambert ve ark çalışmalarında mikronörografi kullanılarak tespit edilen kas sempatik sinir sistem aktivasyonu obez kişilerde normallere göre artmış bulunmuştur $(\mathrm{P}<0.001)(19)$. Vücutta artan adipoz dokunun istirahatte sempatik hiperaktivite ile ilişkili olduğu tartışılmıştır, hatta bazı çalışmalarda obezlerde istirahat halindeki kas sempatik sinir aktivitesinin normalden $\% 50$ daha yüksek olduğu rapor edilmiştir(20, 21, 22). Bu bulgulardan çıkarımımız; muhtemelen VKİ yüksekliği, gece sempatik aktivitenin azalmasını engelliyor, bu da gece kan basıncında beklenen düşüşün olmamasıyla sonuçlanıyor. Çalışmamızda bulduğumuz sonuçlardan biri de VKİ 'leri arttıkça gece sistolik kan basıncı ortalamasının artmasıdır (r:0.389, p:0.021). Bu sonuç da yukarıdaki teorimizi desteklemektedir.

Bu sonuçlar bize VKİ'nin nondipping patern üzerine etkisini göstermektedir. Muhtemelen VKİ si nondipping patern ve morbidite üzerine direk etkilidir. Bu sonuç bize tedavide yol göstermektedir. Hastanın kilo vermesi nondipping patern üzerine etkili olacak, belki de non dipping paterni tedavi edecek, böylece OUAS hastalarında morbidite ve mortaliteyi azaltacaktır.

Çıkar Çatışması ve Finansman Beyanı: Bu çalışmada çıkar çatışması yoktur ve finansman desteği alınmamıştır.

Araştırmacıların Katkı Oranı Beyan Özeti: Yazarlar makaleye eşit katkı sağlamış olduklarını beyan ederler.

\section{KAYNAKLAR}

1. Franklin KA, Lindberg E. Obstructive sleep apnea is a common disorder in the population-a review on the epidemiology of sleep apnea. J Thorac Dis 2015;7:13111322.

2. Heinzer R, Marti-Soler H, Haba-Rubio J. Prevalence of sleep apnoea syndrome in the middle to old age general population. Lancet Respir Med 2016;4:e5-e6.

3. Pickering TG, Shimbo D, Haas D. Ambulatory blood-pressure monitoring. N Engl J Med 2006;354:2368-74

4. Sherwood A, Steffen PR, Blumenthal JA, Kuhn C, Hinderliter AL. Nighttime blood pressure dipping: the role of the sympathetic nervous system. Am J Hypertens. 2002 Feb;15(2 Pt 1):111-8. doi: 10.1016/s0895-7061(01)022518. PMID: 11863245.

5. Staessen JA, Thijs L, Fagard R, O'Brien ET, Clement D, de Leeuw PW, et al. Predicting cardiovascular risk using conventional vs ambulatory blood pressure in older patients with systolic hypertension. Systolic Hypertension in Europe Trial Investigators. JAMA. 1999 Aug 11;282(6):539-46. doi: 10.1001/jama.282.6.539. PMID: 10450715 .

6. Boggia J, Li Y, Thijs L, Hansen TW, Kikuya M, Björklund-Bodegård K,et al.International Database on Ambulatory blood pressure monitoring in relation to Cardiovascular Outcomes (IDACO) investigators. Prognostic accuracy of day versus night ambulatory blood pressure: a cohort study. Lancet. 2007 Oct 6;370(9594):1219-29. doi: 10.1016/S0140-6736(07)61538-4. PMID: 17920917.

7. Sasaki N, Ozono R, Edahiro Y, Ishii K, Seto A, Okita $\mathrm{T}$, et al. Impact of non-dipping on cardiovascular outcomes in patients with obstructive sleep apnea syndrome. Clin Exp Hypertens. 2015;37(6):449-53. doi: 10.3109/10641963.2015.1057833. PMID: 26395950.

8. Soylu AC, Levent E, Sariman N, Yurtlu S, Alparslan S, Saygi A. Obstructive sleep apnea syndrome and anthropometric obesity indexes. Sleep Breath 2012;16:1151-8.

9. Özdilekcan Ç, Özdemir T, Türkkanı MH, Sur HY, Katoue MG. The association of body mass index values with severity and phenotype of sleep-disordered breathing. Tuberk Toraks. 2019 Dec;67(4):265-271. English. doi: 10.5578/ tt.69057. PMID: 32050868.

10. Unger T, Borghi C, Khan NA, Poulter NR, Prabhakaran D, Ramirez A, et al. 2020 International Society of Hypertension Global Hypertension Practice Guidelines. Hypertension. 2020;75:1334-1357.

11. Unal Y, Ozturk DA, Tosun K, Kutlu G. Association between obstructive sleep apnea syndrome and waist-to-height ratio. Sleep Breath. 2019 Jun;23(2):523-529. doi: 10.1007/ s11325-018-1725-4. Epub 2018 Sep 20. PMID: 30238284.

12. Rishi MA, Copur AS, Nadeem R, Fulambarker A. Effect of Positive Airway Pressure Therapy on Body Mass Index in Obese Patients With Obstructive Sleep Apnea Syndrome: A Prospective Study. Am J Ther. 2016 MarApr;23(2):e422-8. doi: 10.1097/MJT.0000000000000072. PMID: 25563675.

13. Johnson KG, Johnson DC, Thomas RJ, Rastegar V, Visintainer P. Cardiovascular and somatic comorbidities and sleep measures using three hypopnea criteria in mild obstructive sleep-disordered breathing: sex, age, and body mass index differences in a retrospective sleep clinic cohort. J Clin Sleep Med. 2020 Oct 15;16(10):16831691. doi: 10.5664/jcsm.8644. PMID: 32620189; PMCID: PMC7954002.

14. Wofford MR, Anderson DC Jr, Brown CA, Jones DW, 
Miller ME, Hall JE. Antihypertensive effect of alpha- and beta-adrenergic blockade in obese and lean hypertensive subjects. Am J Hypertens. 2001 Jul;14(7 Pt 1):694-8. doi: 10.1016/s0895-7061(01)01293-6. PMID: 11465655.

15. Fidan-Yaylali G, Yaylali YT, Erdogan Ç, Can B, Senol H, Gedik-Topçu B, et al. The Association between Central Adiposity and Autonomic Dysfunction in Obesity. Med Princ Pract. 2016;25(5):442-8. doi: 10.1159/000446915. Epub 2016 May 19. PMID: 27194294; PMCID: PMC5639620.

16. Smith MM, Minson CT. Obesity and adipokines: effects on sympathetic overactivity. J Physiol 2012 Apr 15; 590(Pt 8): 1787-1801. Published online 2012 Feb 20. doi: 10.1113/jphysiol.2011.221036

17. Hall JE, Brands MW, Henegar JR, Shek EW: Abnormal kidney function as a cause and a consequence of obesity hypertension. Clin Exper Pharmacol Physiol 1998;25:5864.

18. Tuck ML: Obesity, the sympathetic nervous system, and essential hypertension. Hypertension 1992;19(suppl I):I67-I-77

19. Lambert E, Sari CI, Dawood T, Nguyen J, McGrane M, Eikelis N, et al. Sympathetic nervous system activity is associated with obesity-induced subclinical organ damage in young adults. Hypertension. 2010 Sep;56(3):351-8. doi: 10.1161/HYPERTENSIONAHA.110.155663. Epub 2010 Jul 12. PMID: 20625075.

20. Alvarez GE, Beske SD, Ballard TP, Davy KP. Sympathetic neural activation in visceral obesity. Circulation. 2002 Nov 12;106(20):2533-6. doi: 10.1161/01. cir.0000041244.79165.25. PMID: 12427647.

21. Sivenius K, Niskanen L, Laakso M, Uusitupa M. A deletion in the alpha2B-adrenergic receptor gene and autonomic nervous function in central obesity. Obes Res. 2003 Aug;11(8):962-70. doi: 10.1038/oby.2003.133. PMID: 12917501.

22. Grassi G, Dell'Oro R, Facchini A, Quarti Trevano F, Bolla GB, Mancia G. Effect of central and peripheral body fat distribution on sympathetic and baroreflex function in obese normotensives. J Hypertens. 2004 Dec;22(12):23639. doi: 10.1097/00004872-200412000-00019. PMID: 15614031 . 